\title{
THE EFFECT OF THE PRESENCE OF EPILEPTIC ATTACKS ON THE CLINICAL DURATION OF SUPRATENTORIAL BRAIN MENINGIOMAS
}

DOI: 10.36740/WLek202003126

\author{
Taras 0. Studeniak, Volodymyr I. Smolanka, Olesya I. Borovik \\ DEPARTMENT OF NEUROLOGY, NEUROSURGERY AND PSYCHIATRY, FACULTY OF MEDICINE, UZHHOROD NATIONAL UNIVERSITY, UZHHOROD, UKRAINE
}

\begin{abstract}
The aim: To study the effect of epileptic seizures in patients with supratentorial brain meningiomas on the clinical course of meningiomas in the early and late postoperative period. Materials and methods: A retrospective analysis of the course of the disease was performed in 242 patients with total removed supratentorial meningioma of the brain (general group). Long-term outcome of the disease was estimated in 176 people (a catamnesis group).

Results: The occurrence of a new neurological deficit was observed in 18 (18.0 $\pm 3.8 \%)$ patients out of 100 among patients with epileptic seizures before surgery and in 19 $(13.4 \pm 2.9 \%)$ out of 142 among those who had no seizures. The mortality rate was $1(1.0 \pm 1.0 \%)$ in the group of patients with seizures and $3(2.8 \pm 1.4 \%)$ in the group of patients without seizures before surgery.

The prevalence of new neurological deficits in the catamnesis group is 14 (19.2 $\pm 4.6 \%)$ of 73 patients with epileptic seizures before surgery and 17 (16.5 $\pm 3.7 \%)$ of 103 patients without seizures. Mortality was 3 cases $(4.1 \pm 2.3 \%)$ in patients with seizures and 9 cases $(8.7 \pm 2.8 \%)$ among patients without seizures.

Conclusions: No data have been obtained that the presence of epileptic seizures affects the incidence of new neurological deficits, complications and mortality after surgical treatment of meningiomas in the early and late postoperative period.
\end{abstract}

KEY WORDS: Epilepsy, meningioma, seizure, long-term follow-up

Wiad Lek. 2020;73(3):541-545

\section{INTRODUCTION}

Meningioma is the most common intracranial tumour, with an incidence of 10.26 and 4.55 cases per 100,000 adults in women and men, respectively [1]. Often meningioma is manifested by seizures that significantly reduce the quality of life of the patient [2]. Surgical treatment is the method of choice in patients with newly diagnosed meningiomas [3]. Surgical treatment usually relieves the patient of the disease, but in some patients persists or occurs after the intervention of a particular neurological deficiency, as well as the possible complications of surgical treatment [4]. For patients with meningiomas who have a good long-term prognosis for life after surgery, this is especially important [5]. Research into the factors that influence the clinical course of meningioma after surgical treatment will optimize treatment tactics for this group of patients.

In 2017, a meta-analysis on the course of epilepsy in brain meningiomas reported that in the last 35 years, only 4 studies were directed to a detailed study of seizures in patients with meningiomas in pre- and postoperative periods [6]. Usually, studies have been performed that are more focused on determining surgical tactics and studying the predictors of prolonged growth than on determining the course of epileptic seizures. However, a number of publications have noted the prevalence and progression of patients. There have been a number of predictors of the persistence of seizures after surgery, such as swelling around the tumour and the male $[7,8,9]$.
The study of the impact of epileptic seizures on the disease clinic in patients operated on for supratentorial meningioma will more accurately predict the course of the disease and, accordingly, may affect medical and surgical treatment. Previously, the authors analysed the group of patients with 110 people, but the study was more focused on the course of the epileptic seizures themselves [10].

\section{THE AIM}

The aim of the study was to investigate the effect of epileptic seizures in patients with supratentorialin brain meningiomas on the clinical course of the disease in the early and late postoperative period, with a view to further predicting the disease.

\section{MATERIALS AND METHODS}

A retrospective analysis of case histories of patients operated on for supratentorial brain meningioma was conducted at the Municipal Non-Profit Enterprise "Regional Clinical Center of Neurosurgery and Neurology" of Transcarpathian Regional Council, Ukraine from January 2006 to December 2017.

The study was approved by the local ethics committee of Municipal Non-Profit Enterprise "Regional Clinical Center for Neurosurgery and Neurology" of Transcarpathian Regional Counsil, Ukraine (protocol No. 115 of 12/18/2018) and performed in accordance with the provisions of the Declaration of Helsinki. All patients provided informed consent to the processing of their personal data in the study. 
Table I. Basic clinical and instrumental characteristics of patients in the general group and the catamnesis group

\begin{tabular}{|c|c|c|c|}
\hline \multicolumn{2}{|c|}{ Main group } & Main group & Catamnesis group \\
\hline \multicolumn{2}{|c|}{ Number of patients } & 242 & 176 \\
\hline \multicolumn{2}{|c|}{ Average age (years) } & $53.8 \pm 0.8$ & $53.5 \pm 1.0$ \\
\hline \multirow{2}{*}{ The distribution by sex } & Men & $79(31.8 \pm 3.0 \%)$ & $56(31.8 \pm 3.5 \%)$ \\
\hline & Women & $163(68.2 \pm 3.0 \%)$ & $120(68.2 \pm 3.5 \%)$ \\
\hline \multirow{6}{*}{ The distribution by age } & 20-30 years & $12(5.0 \pm 1.5 \%)$ & $11(6.3 \pm 1.8 \%)$ \\
\hline & $31-40$ years & $22(9.1 \pm 1.8 \%)$ & $19(10.8 \pm 2.3 \%)$ \\
\hline & $41-50$ years & $55(22.5 \pm 2.7 \%)$ & $41(23.3 \pm 3.2 \%)$ \\
\hline & $51-60$ years & $75(31.1 \pm 3.0 \%)$ & $44(25.0 \pm 3.3 \%)$ \\
\hline & $61-70$ years & $57(23.6 \pm 2.7 \%)$ & $43(24.4 \pm 3.3 \%)$ \\
\hline & 71 and more & $21(8.7 \pm 1.8 \%)$ & $18(10.2 \pm 2.3 \%)$ \\
\hline \multirow{7}{*}{ The distribution by localization } & Upper-lateral surface & $95(39.3 \pm 3.1 \%)$ & $66(37.5 \pm 3.7 \%)$ \\
\hline & Wings of wedge-shaped bone & $60(24.8 \pm 2.8 \%)$ & $46(26.1 \pm 3.3 \%)$ \\
\hline & Sickle of the brain & $51(21.1 \pm 2.6 \%)$ & $42(23.9 \pm 3.2 \%)$ \\
\hline & Hump of the saddle & $13(5.7 \pm 1.5 \%)$ & $10(5.7 \pm 1.8 \%)$ \\
\hline & Perforating bones & $15(5.4 \pm 1.6 \%)$ & $8(4.5 \pm 1.6 \%)$ \\
\hline & Lateral ventricle & $5(2.1 \pm 0.9 \%)$ & $3(1.7 \pm 1.0 \%)$ \\
\hline & Lateral furrow & $3(1.2 \pm 0.7 \%)$ & $1(0.6 \pm 0.6 \%)$ \\
\hline \multirow{3}{*}{ The distribution by histology } & Grade I & $197(81.4 \pm 2.5 \%)$ & $138(78.4 \pm 3.1 \%)$ \\
\hline & Grade II & $34(14.1 \pm 2.2 \%)$ & $28(15.9 \pm 2.8 \%)$ \\
\hline & Grade III & $11(4.5 \pm 1.3 \%)$ & $10(5.7 \pm 1.8 \%)$ \\
\hline \multirow{3}{*}{$\begin{array}{l}\text { The distribution by size } \\
\text { (maximum diameter)* }\end{array}$} & Less than $30 \mathrm{~mm}$ & $50(24.8 \pm 3.6 \%)$ & $35(23.3 \pm 3.5 \%)$ \\
\hline & $30-59 \mathrm{~mm}$ & $118(58.4 \pm 8.3 \%)$ & $87(58.0 \pm 4.0 \%)$ \\
\hline & More than $60 \mathrm{~mm}$ & $34(16.8 \pm 2.4 \%)$ & $28(18.7 \pm 3.2 \%)$ \\
\hline
\end{tabular}

Note: * - tumour sizes were analysed in 202 patients in the general group and 150 patients in the history group. The proportion was calculated in each individual distribution

Data on the clinical course of meningiomas before and immediately after surgery were obtained for 242 patients from whom a general group was formed. Long-term clinical outcome was evaluated in 176 patients who were referred to as a catamnesis group.

Inclusion criteria. Tumour localization over brain tent, primary surgery, and total tumour removal (Simpson I-III).

Exclusion criteria. Tumour localization below the brain tent, subtotal or partial removal, prolonged tumour growth, and multiple meningiomas.

All 242 patients underwent total removal of Simpson I-III meningioma. Each patient underwent postoperative neuroimaging control in the form of an MRI or CT scan.

Long-term treatment outcomes were evaluated in 176 out of 242 patients ( $72.7 \%$ of the total group). It was decided to call this group of 176 patients a group of catamnesis. The average duration of observation was 37.0 months. The duration of observation was at least 6 months for each patient. The maximum duration of observation was 111 months.

The main clinical and instrumental characteristics of patients in the general group and the group of history are given in Table I.

All patients in the general group were divided into two subgroups. The first subgroup included 100 patients with brain meningiomas and concomitant epileptic seizures, and the second group included 142 patients with meningiomas who had no epileptic seizures before surgery. Diagrammatic distribution of patients is shown in Figure 1.

A subgroup of patients with epileptic seizures and a group of patients without epileptic seizures were compared. Whether the presence of epileptic seizures on the likelihood of developing neurological deficits and complications after surgical treatment in the early period has been investigated.

All patients of the history group were divided into two subgroups. The first subgroup included 73 patients with brain meningiomas and concomitant epileptic seizures before surgery, and the second subgroup had 103 patients with meningiomas who did not have epileptic seizures before surgery. Diagrammatic distribution of patients is shown in Figure 2.

A subgroup of patients with epileptic seizures (further group 1) and a group of patients without epileptic seizures (further group 2 ) were compared. It has been investigated whether epileptic seizures affect the likelihood of developing neurological deficits and complications in the long term after surgical treatment.

Statistical data processing was performed using Excel spreadsheets Windows-2007 license number 00426-OEM8992662-00400, which is included in the Microsoft Office 2003 suite of programs, and STATISTICA license number ZZS999000009906307-DEMO5. Statistical analysis of 

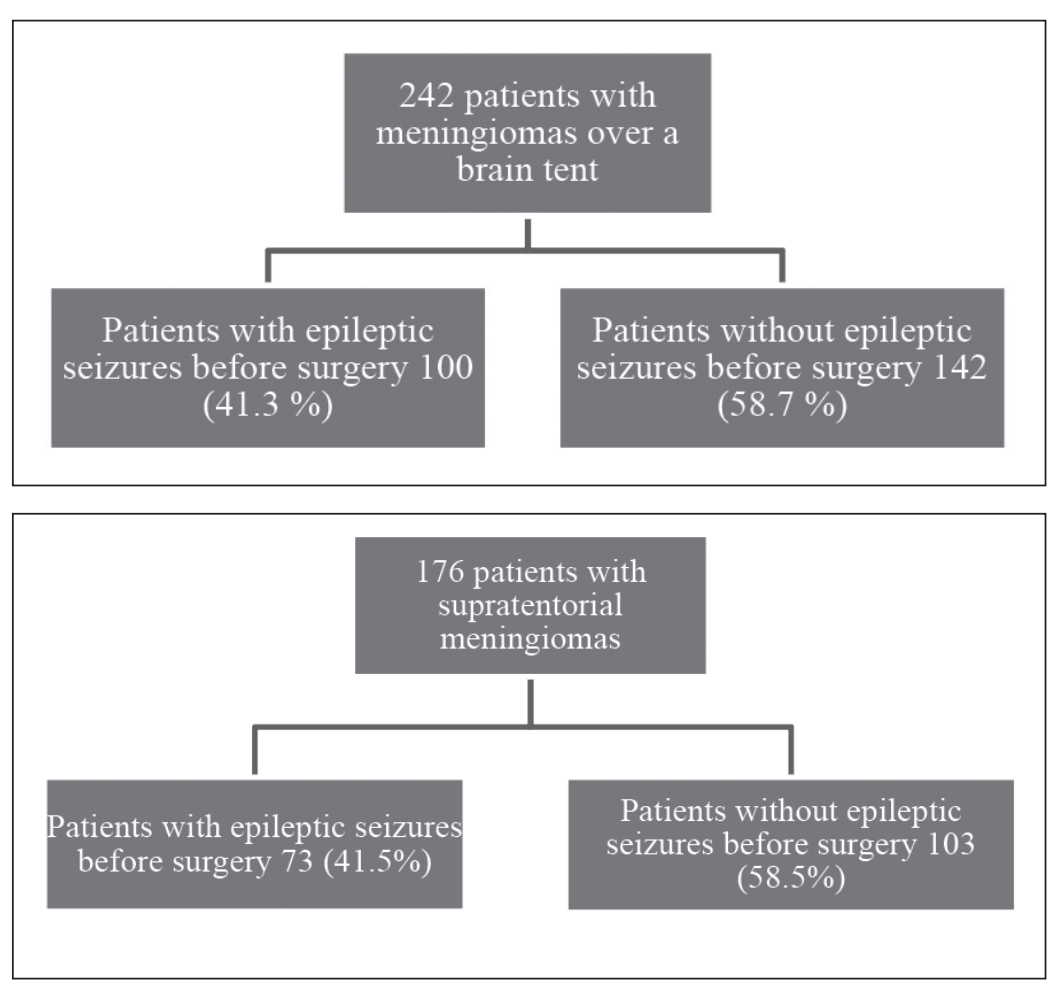

Fig. 1. The distribution of patients in the general group into subgroups

Fig. 2. Distribution of patients of the catamnesis group into subgroups materials, summary of results and generalization of conclusions, performed by the method of variational statistics, taking into account the mean values (fashion, median, arithmetic mean) and mean error $(M)$, also searched for a reliable difference between the groups $(\mathrm{p})$.

\section{RESULTS}

At hospitalization, neurological deficits were presented in $113(46.7 \pm 3.2 \%)$ patients. At the time of discharge, neurological deficits persisted in $93(38.4 \pm 3.1 \%)$ patients, including 37 patients $(15.2 \pm 2.3 \%)$ that had a new neurological deficit. New neurological deficits were most often manifested by hemiparesis and speech disorders, but in the most cases, these symptoms were due to postoperative cerebral edema and gradually regressed. Improvement in neurological status was observed in 61 patients $(25.2 \pm 2.8$ $\%)$. In addition, it should be noted that one patient might have more than one clinical symptom.

Among patients who did not have a pre-intervention deficit, it occurred in $22(17.1 \pm 3.3 \%)$ patients out of 129 . In $61(51.3 \pm 4.5 \%)$ of the 119 patients who had a neurological deficit before the intervention there was an improvement or the deficit regressed completely. A deficit increase was observed in $15(13.3 \pm 3.2 \%)$ cases out of 113 .

Complications in the early postoperative period were in 9 patients, in 2 patients there were hematomas of the tumour bed, resulting in repeated surgery. One patient underwent reoperation for nasal liquor. The flap infection was in one patient and required surgical removal, followed by a skull bone defect. Another patient had pulmonary embolism on the 2 nd postoperative day. Another patient with meningioma of the middle third of the sickle of the brain had a venous stroke in the early postoperative period, which resulted in a fatal outcome. Another patient with major menigioma also had a venous stroke followed by a fatal end in the region of the upper-lateral surface of the large hemisphere. In two patients with large meningiomas of the wing of the wedge bone, malignant ischemic stroke in the middle cerebral artery pool developed in the early postoperative period, leading to death. The total postoperative mortality was $4(1.7 \pm 0.9 \%)$ patients.

The comparison of early surgical results in the group of patients with epileptic seizures before surgery (100 patients) with the group of patients without epileptic seizures (142 patients).

Among patients with epileptic seizures prior to surgery, neurological deficits were observed in 29 patients out of 100 , whereas in the non-seizure group, 84 out of 142 . The proportion of patients with neurological deficits was $29.0 \pm 4.5 \%$ and $59.2 \pm 4.1 \%$ respectively, that is, in patients without epileptic seizures, neurological deficits occurred more often $\mathrm{p}<0.01$. At the time of discharge, neurological deficits were observed in 29 patients in the epileptic seizure group and in 64 patients in the seizure group, which were $29.0 \pm 4.5 \%$ and $45.1 \pm 4.2 \%$, respectively.

An increase in previous or new neurological deficits was observed in 18 patients from the group of patients with epileptic seizures, and 19 among them, who had no attacks, which was $18.0 \pm 3.8 \%$ and $13.4 \pm 2.9 \%$ respectively in each group.

Among 9 patients with early complications, 2 had patients who had epileptic seizures before surgery ( 1 case of stroke in the middle cerebral artery and 1 case of hematoma of the tumour bed), and 7 patients who had no seizures. Accordingly, the prevalence of early complications was $2.0 \pm 1.4 \%$ among patients with seizures and $4.9 \pm 1.8 \%$ in the group of patients without seizures. 
Table II. Comparison of study groups regarding the early onset of additional neurological deficits, complications and mortality

\begin{tabular}{ccccc} 
& \multicolumn{2}{c}{$\begin{array}{c}\text { Group with epileptic seizures before surgery } \\
\mathbf{N = 1 0 0}\end{array}$} & \multicolumn{2}{c}{$\begin{array}{c}\text { Group without epileptic seizures before } \\
\text { surgery } \mathbf{N = 1 4 2}\end{array}$} \\
\cline { 2 - 5 } & Number & Percentage & Number & Percentage \\
\hline New deficit & 18 & $18.0 \pm 3.8 \%$ & 19 & $13.4 \pm 2.9 \%$ \\
\hline Early complications & 2 & $2.0 \pm 1.4 \%$ & 7 & $4.9 \pm 1.8 \%$ \\
\hline Postoperative mortality & 1 & $1.0 \pm 1.0 \%$ & 3 & $2.8 \pm 1.4 \%$ \\
\hline
\end{tabular}

Table III. Comparison of study groups on the retention of additional neurological deficits and long-term mortality

\begin{tabular}{ccccc}
\hline & \multicolumn{2}{c}{ Group with epileptic seizures before surgery } & \multicolumn{2}{c}{$\begin{array}{c}\text { Group without epileptic seizures before } \\
\text { surgery } \mathbf{N = 1 0 3}\end{array}$} \\
\cline { 2 - 5 } & Number & Percentage & Number & Percentage \\
\hline New deficit & 14 & $19,2 \pm 4,6 \%$ & 17 & $16,5 \pm 3,7 \%$ \\
\hline Mortality & 3 & $4,1 \pm 2,3 \%$ & 9 & $8,7 \pm 2,8 \%$ \\
\hline
\end{tabular}

It should be noted that among 4 deaths, 1 was in the group of patients with seizures and 3 in the group of patients without seizures before surgery. In percentage terms, it is $1.0 \pm 1.0 \%$ and $2.8 \pm 1.4 \%$, respectively. Comparison of new neurological deficits, complications, and mortality rates between the study groups are shown in Table II.

It is clear that complications and postoperative mortality are higher in patients without seizures. This difference can be explained by the fact that neoplasms that are manifested by epileptic seizures are characterized by a smaller average tumour size, and rarely have another neurological deficit. In addition, overall, skull-based localization is less commonly associated with convulsions, and for meningiomas of the saddle, seizures in general are quite rare. However, no statistically significant difference between the groups revealed $p>0.05$.

When processing long-term results, it is noted that most neurological symptoms in patients gradually regress. In the distant period, 32 patients $(47.8 \pm 6.1 \%)$ of 67 patients who had a neurological deficit at the time of discharge were completely gone, but the situation is different for different neurological symptoms. Paresis was preserved only in 17 patients (37.8 \pm 7.2 $\%)$ of the 45 who had it at the time of discharge, i.e. it regressed in almost $2 / 3$ of cases, whereas visual disturbances occurred only in 4 patients $(26,7 \pm 11.8 \%)$ of the 15 who had them at the time of discharge. These results suggest that visual impairment is most predictably unfavourable to recovery.

The effect of epileptic seizures before surgery on neurological deficits in the early and long post-operative period was analysed.

Long-term paresis was observed in 5 of 14 patients who had them at the time of discharge in the group of patients with convulsions and in 12 of 31 patients who did not have a seizures before surgery. According to those patients who had paresis at discharge at the time of discharge, it was maintained in $35.7 \pm 13.3 \%$ of persons in the seizure group and in $38.7 \pm 8.8$ $\%$ among patients without seizures. With regard to other types of clinical symptoms, the dynamics were practically the same or the number of patients was small for qualitative statistical analysis and no significant difference was found between the study groups. The findings suggest that there is no difference in the recovery of neurological deficits, depending on whether or not there were epileptic seizures prior to surgery.

When determining the dynamics of neurological deficits, without differentiating between different clinical symptoms in the distant period, deficiency was present only in $32(18.2 \pm 2.9$ $\%)$ patients in 176. Most often, the lack of dynamics of neurological deficits was associated with visual impairment. The occurrence of a new neurological deficit or an increase in the previous deficit was usually seen in patients with vascular complications. Among 67 patients who had a neurological deficit at the time of hospital discharge, $32(47.8 \pm 6.1 \%)$ persisted for a long period.

Among 104 patients who did not have a neurological deficit before the intervention, in the long term, it was only found in 5 people $(4.8 \pm 2.1 \%)$. In contrast, 26 patients $(36.1 \pm 5.1 \%)$ of 72 had a deficiency among patients who had clinical symptoms before surgery. This could be explained by the fact that new neurological deficits are often due to postoperative edema or temporary vascular disorders, whereas neurological deficiency before surgery is often caused by an already formed organic CNS lesion.

Upon receipt of the catamnesis, 12 (6.8 $\pm 1.9 \%)$ of 176 patients were found to have died.

In 4 patients, death occurred as a result of various vascular complications in the early postoperative period, as described in detail in the section on evaluation of early results of surgical treatment. Another 4 patients died of cardiovascular disease (including one patient with myocardial infarction 2 months after meningioma removal). Two patients died of cancer. One patient died due to prolonged tumor growth. One patient died of a malignant tumor (not meningioma) of the brain.

It is resolved to compare long-term findings on neurological deficits and mortality among patients who had epileptic seizures before surgery (73 people in the catamnesis group) and did not have a trial before the intervention (103 people in the catamnesis group) (Table III). The table III, shows that in the long-term period new postoperative deficits were maintained at approximately the same level in both groups, while comparing the study groups for mortality, 9 patients were from the group 
of patients without epileptic seizures, and 3 in the group of meningiomas with concomitant seizures. These data are most likely because patients with no convulsions were characterized by a higher incidence of early postoperative complications, but no significant difference was found between the groups.

\section{DISCUSSION}

The analysis of the clinical course of the disease in a large group of patients with supratentorial meningiomas in the early and late period after surgical treatment. Despite the significant difference in the groups regarding the prevalence of neurological deficit before surgery, there was no significant effect of the presence of epileptic seizures on the likelihood of neurological deficit, complications and mortality. On the other hand, performing the study on more patients can potentially lead to more recent data.

It should be noted that one feature is in the group of patients who had a neurological deficit before surgery. Who, at the time of discharge, had a neurological deficit assessed as "unchanged" in the future, usually had no improvement. Improvement was observed in those patients who at the time of discharge were already positive dynamics or, conversely, had a worsening in neurological status.

One of the major limitations of the study is the lack of analysis of the linkage of clinical complications with more than one factor, not just seizures alone. Perhaps some clinical sign in conjunction with convulsions will be prognostically unfavourable. This creates a potential field for new research.

A prospective study of the effect of epileptic seizures on the clinical course of supratentorial meningiomas in the brain is potentially needed.

It can be argued that the long-term results of surgical treatment are different from those at the time of discharge. In almost half of the patients who had a neurological deficit at the time of discharge, it disappears in the long term. The situation is better in the case of paresis, which disappears in approximately $2 / 3$ of patients, and worse in the case of visual disturbances, in which the regression of symptoms occurs only in $1 / 3$ of cases.

\section{CONCLUSIONS}

The long-term clinical results of surgical treatment of supratentorial meningiomas are significantly better than earlier. In almost half of the patients who had a neurological deficit at the time of discharge, it disappears in the long-term period. The situation is better in the case of paresis, which disappears in approximately $2 / 3$ of patients, and worse in the case of visual disturbances, in which the regression of symptoms occurs only in $1 / 3$ of cases.

No data have been obtained that the presence of epileptic seizures affects the likelihood of developing neurological deficits, complications and mortality after surgical treatment of meningiomas in the early and late postoperative period.

\section{REFERENCES}

1. Chen DY, Chen CC, Crawford JR et al. Tumor-related epilepsy: epidemiology, pathogenesis and management. Journal of NeuroOncology. 2018;139(1):13-21. doi: 10.1007/s11060-018-2862-0

2. ILAECommission Report.5th International Course on epilepsy: Surgically Remedial Epilepsies. Venicia; 2006, p. 7-13.
3. Rogers L, Barani I, Chamberlain M, et al. Meningiomas: knowledge base, treatment outcomes, and uncertainties. A RANO review. Journal of Neurosurgery. 2015;122(1):4-23. doi: 10.3171/2014.7.jns131644

4. Baulac M, de Boer H, Elger Cet al. Epilepsy priorities in Europe: A report of the ILAE-IBE Epilepsy Advocacy Europe Task Force. Epilepsia. 2015;56 (11):1687-1695. doi: 10.1111/epi.13201

5. Behr C, Goltzene MA, Kosmalski G et al. Epidemiology of epilepsy. Revue Neurologique. 2016;172(1):27-36. doi: 10.1016/j.neurol.2015.11.003

6. Englot DJ, Magill ST, Han SJ et al. Seizures in supratentorial meningioma: a systematic review and meta-analysis. Journal of Neurosurgery. 2016;124(6):1552-1561. doi: 10.3171/2015.4.jns 142742

7. DeAngelis LM Brain Tumors. New England Journal of Medicine. 2001;344 (2):114-123. doi: 10.1056/nejm200101113440207

8. Berhouma M, Jacquesson T, Jouanneau E Pathogenesis of peritumoral edema in intracranial meningiomas. Neurosurgical Review. 2017;42(1):59-71. doi: 10.1007/s10143-017-0897-x

9. Sultan A, Morsy M, El-Saadany W et al. Predictive factors for seizures accompanying intracranial meningiomas. Asian Journal of Neurosurgery. 2019;14(2):403-409. doi: 10.4103/ajns.ajns_152_18

10. Studeniak T, Smolanka V, Smolanka A Viddaleni naslidki hirurgichnogo likuvannya meningiom. Analiz 110 vipadkiv [Long-term results of meningiomas surgical treatment. Analysis of 110 cases]. ScienceRise: Medical Science. 2018;4(24):32-37. doi: 10.15587/25194798.2018.132680 (In Ukrainian)

"Diagnosis, treatment and prognosis of the development of symptomatic epilepsy in patients with neurosurgical diseases. Number State registration 0110U002528."

"Genetic and clinical-electrophysiological criteria for the prediction of the effectiveness of pharmacotherapy for epilepsy. Number State registration 0110U000398."

\section{ORCID and contributionship:}

Taras O. Studeniak - 0000-0001-6564-1552 A, B, C, D, E

Olesya I. Borovik - 0000-0001-8918-5125 ${ }^{\text {B, }}$

Volodymyr I. Smolanka - 0000-0001-7296-8297 ${ }^{F}$

Conflict of interest:

The Authors declare no conflict of interest:

\section{CORRESPONDING AUTHOR Taras 0. Studeniak \\ Kapushanska str 24, 88018, \\ Ukraine, Uzhhorod \\ e-mail:sttaras@yahoo.com}

Received: 17.01 .2020

Accepted: 05.03 .2020

A - Work concept and design, B - Data collection and analysis, C - Responsibility for statistical analysis, D-Writing the article, $\mathbf{E}$-Critical review, $\mathbf{F}$-Final approval of the article 